\title{
IMPACT OF CASTING SPEED ON MOULD WALL TEMPERATURE FIELD
}

\author{
${ }^{1}$ Luboš POLCAR, ${ }^{1}$ René PYSZKO \\ ${ }^{1}$ VSB - Technical University of Ostrava, Ostrava, Czech Republic, EU \\ lubos.polcar@vsb.cz, rene.pyszko@vsb.cz
}

https://doi.org/10.37904/metal.2020.3457

\begin{abstract}
Production of new steel grades and growing demands on productivity require an increasing understanding of heat transfer during the continuous casting process. This work is focused on a mould which has a great influence on the casting process and the final quality of billets. Casting speed has to be adapted to the steel parameters and the format of the product. The temperature field of the mould changes with the casting speed. From the temperature field, the contact of the solid shell with the mould insert and the intensity and symmetry of heat removal can be deduced. Temperature measurements were conducted in the mould walls on site. It was found that increasing the casting speed reduced the temperature gradient in the longitudinal direction and caused a decrease in the unevenness of the temperature field in the transverse direction, which was expressed by the so-called thermal axis. A percentage increase in mould temperatures that followed the increase in casting speed, exhibited close to a linear dependency on the distance from the mould top. Based on the presented data, the increase in casting speed caused a more uniform temperature field in the mould insert, which is related to a more uniform heat removal from the billet.
\end{abstract}

Keywords: Continuous casting, mould, temperature field, thermal axis

\section{INTRODUCTION}

Continuous casting of steel provides a highly economical and compact manufacturing process. A total heat removal in the primary, secondary and tertiary cooling zones must be sufficient to solidify the steel in its entire cross-section before reaching the cutting equipment [1]. Although an optimal cooling rate by water jets in the secondary zone is important from a point of view of the product quality [2] initial defects already occur in the primary zone, i.e. in the mould. Mould serves as a heat exchanger between the solidifying steel and the cooling water. Main purpose of the mould is to remove a sufficient amount of heat in order to create a solid shell able to withhold pressure of a strand liquid core and other loads when it leaves the mould. A working side of the mould insert can reach temperatures over $400{ }^{\circ} \mathrm{C}$ near the meniscus, where the most significant deformation of the wall occurs [3]. The highest heat load of the mould can be observed at high casting speed [4,5].

In order to decrease a wear of the mould a casting powder is applied around a circumference of the solidifying steel. Casting powder affects the heat transfer considerably. It alternately melts and solidifies depending on a local temperature in a gap between the shell and the mould. Therefore it can introduce another harder to predict irregularity into the heat transfer process. Shape of the mould also impacts the heat transfer process. Heat removal uniformity in the mould is limited by shrinkage of the solidifying steel which leads to an increase in the gap between the mould and the solid shell. This phenomenon is most noticeable in corners of the mould. For this reason a mass of solidifying steel shall be centred in order to reach a uniformity of the heat transfer. This can be adjusted by a geometrical setting of the casting machine. A position of the solidifying strand in the casting machine dynamically changes in time and also depends on casting and cooling parameters. The uneven heat removal in the mould is reflected in the temperature field of the mould walls. This research was based on on-site measurements that were conducted during the manufacturing process. The paper provides 
information on a consequence of increasing the casting speed on the temperature field of the mould wall in longitudinal and transversal directions.

\section{EXPERIMENTAL DATA}

Measurements were conducted in a radial billet casting machine of the format $150 \times 150 \mathrm{~mm}$. Total length of the mould is $1 \mathrm{~m}$ and its wall thickness is $13 \mathrm{~mm}$. A surface of molten steel was kept at the distance of $140 \mathrm{~mm}$ below a mould top. In the longitudinal centreline of each wall there were installed five thermocouples (as can be seen in Figure 1) in a depth of $2 \mathrm{~mm}$ from the working surface. The distances of thermocouples from the top of the mould were $250 \mathrm{~mm}, 400 \mathrm{~mm}, 550 \mathrm{~mm}, 700 \mathrm{~mm}$ and $850 \mathrm{~mm}$. The measurement system provided data acquisition with a sampling period of $1 \mathrm{~s}$. The walls are marked from the point of view of the operator standing in front of the mould as left side (LS), right side (RS), outer radius (OR) and inner radius (IR).

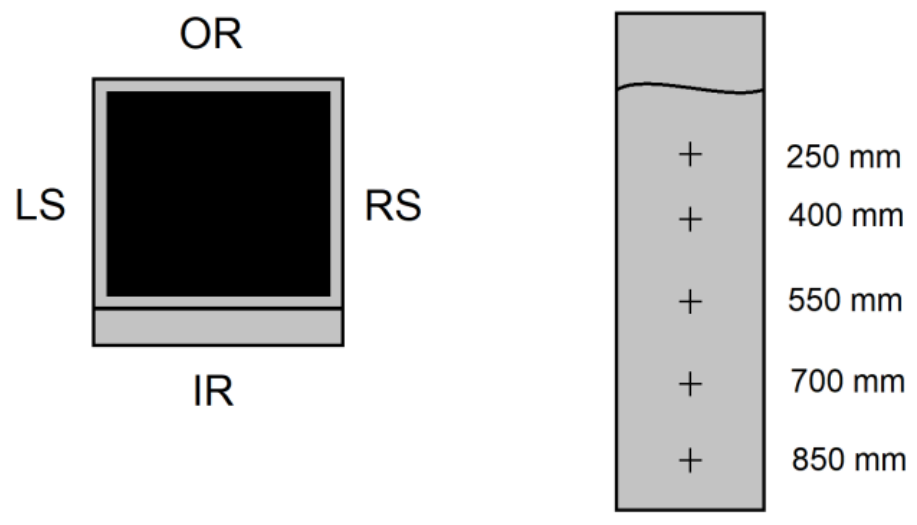

Figure 1 Layout of a mould description and thermocouple installation locations

For further evaluation casting of low carbon steel of chemical composition in Table 1 was selected. Cooling water flow rate was kept at a constant value and also temperature of liquid steel in a tundish was measured at the constant value.

Table 1 Main elements of the steel chemical composition

\begin{tabular}{|c|c|c|c|c|c|c|c|c|c|}
\hline Element & $\mathrm{C}$ & $\mathrm{Mn}$ & $\mathrm{Si}$ & $\mathrm{P}$ & $\mathrm{S}$ & $\mathrm{Cu}$ & $\mathrm{Cr}$ & $\mathrm{Ni}$ & Mo \\
\hline wt.\% & 0.074 & 1.46 & 0.877 & 0.013 & 0.008 & 0.04 & 0.06 & 0.03 & 0.006 \\
\hline
\end{tabular}

\section{DATA EVALUATION}

For evaluation, two time intervals of casting were selected when the casting speed was almost constant at values 2.31 and $2.67 \mathrm{~m} \cdot \mathrm{min}^{-1}$. As an on-site measurement system recorded a wide range of data, a further processing was therefore necessary. For both casting speeds, value of arithmetic mean and standard deviation of temperatures were evaluated during 8.5 minute time intervals, which represent 512 samples for each temperature sensor, see Table 2.

Temperatures from the Table 2 can be seen also in the form of graphs in Figure 2. It is evident that with an increasing distance from the meniscus, the temperatures of the wall mostly tend to significantly decrease. An exception can be seen in RS and LS walls in the depths of $850 \mathrm{~mm}$. A great difference occurs when the IR and OR are compared. The outer radius side of the mould is in more intense contact with the solidifying shell.

The absolute temperature differences at all measuring points after increasing the casting speed can be seen in Figure 3. 
Table 2 Mean values and standard deviations of measured temperatures

\begin{tabular}{|c|c|c|c|c|c|c|c|}
\hline \multirow[b]{2}{*}{ Mould wall } & \multicolumn{6}{|c|}{ Distance from mould top } & \multirow{2}{*}{$\begin{array}{c}\text { Casting } \\
\text { speed } \\
\left(\mathrm{m} \cdot \mathrm{min}^{-1}\right)\end{array}$} \\
\hline & & $\begin{array}{l}\text { pos. No. } 1 \\
250(\mathrm{~mm})\end{array}$ & $\begin{array}{l}\text { pos. No. } 2 \\
400(\mathrm{~mm})\end{array}$ & $\begin{array}{l}\text { pos. No. } 3 \\
550(\mathrm{~mm})\end{array}$ & $\begin{array}{l}\text { pos. No. } 4 \\
700(\mathrm{~mm})\end{array}$ & $\begin{array}{l}\text { pos. No. } 5 \\
850(\mathrm{~mm})\end{array}$ & \\
\hline \multirow{4}{*}{ LS } & $t\left({ }^{\circ} \mathrm{C}\right)$ & 157.1 & 141.1 & 124.7 & 112.0 & 112.1 & \multirow{2}{*}{2.31} \\
\hline & $\sigma\left({ }^{\circ} \mathrm{C}\right)$ & 8.0 & 7.3 & 7.8 & 8.7 & 9.9 & \\
\hline & $t\left({ }^{\circ} \mathrm{C}\right)$ & 159.5 & 140.9 & 125.6 & 113.6 & 111.9 & 267 \\
\hline & $\sigma\left({ }^{\circ} \mathrm{C}\right)$ & 7.3 & 7.6 & 8.3 & 7.9 & 9.6 & 2.01 \\
\hline \multirow{4}{*}{ RS } & $t\left({ }^{\circ} \mathrm{C}\right)$ & 164.4 & 111.4 & 96.3 & 90.0 & 93.4 & \multirow{2}{*}{2.31} \\
\hline & $\sigma\left({ }^{\circ} \mathrm{C}\right)$ & 8.6 & 10.0 & 10.5 & 9.5 & 9.5 & \\
\hline & $t\left({ }^{\circ} \mathrm{C}\right)$ & 173.2 & 120.0 & 107.3 & 102.1 & 107.1 & 267 \\
\hline & $\sigma\left({ }^{\circ} \mathrm{C}\right)$ & 7.5 & 9.4 & 9.8 & 8.2 & 8.4 & 2.01 \\
\hline \multirow{4}{*}{ OR } & $t\left({ }^{\circ} \mathrm{C}\right)$ & 154.5 & 125.5 & 116.8 & 109.4 & 108.6 & \multirow{2}{*}{2.31} \\
\hline & $\sigma\left({ }^{\circ} \mathrm{C}\right)$ & 5.8 & 7.5 & 8.5 & 8.8 & 9.6 & \\
\hline & $t\left({ }^{\circ} \mathrm{C}\right)$ & 157.9 & 129.6 & 121.7 & 115.3 & 116.0 & \\
\hline & $\sigma\left({ }^{\circ} \mathrm{C}\right)$ & 6.4 & 7.7 & 8.8 & 9.3 & 9.9 & 2.01 \\
\hline \multirow{4}{*}{ IR } & $t\left({ }^{\circ} \mathrm{C}\right)$ & 150.9 & 122.0 & 112.8 & 96.8 & 91.9 & \multirow{2}{*}{2.31} \\
\hline & $\sigma\left({ }^{\circ} \mathrm{C}\right)$ & 6.5 & 8.8 & 9.9 & 8.5 & 7.4 & \\
\hline & $t\left({ }^{\circ} \mathrm{C}\right)$ & 156.0 & 127.0 & 120.5 & 106.2 & 104.9 & \multirow{2}{*}{2.67} \\
\hline & $\sigma\left({ }^{\circ} \mathrm{C}\right)$ & 7.1 & 9.0 & 10.0 & 7.8 & 8.6 & \\
\hline
\end{tabular}
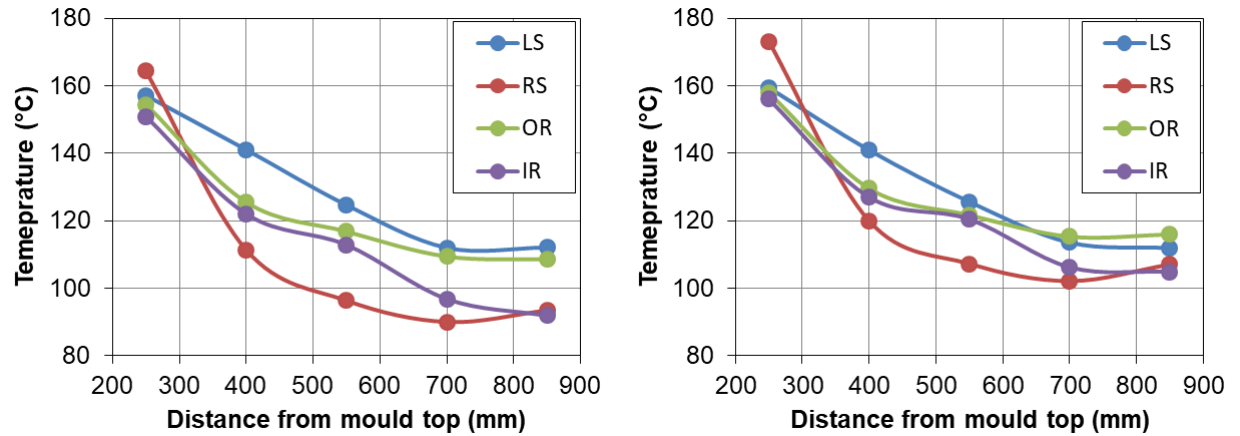

Figure 2 Measured temperatures for the casting speed 2.31 (left) and $2.67 \mathrm{~m} \cdot \mathrm{min}^{-1}$ (right)

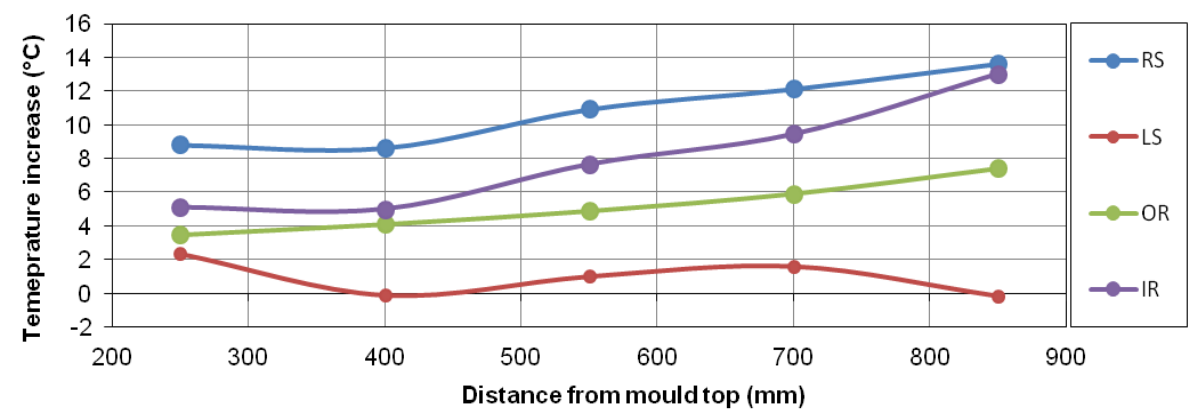

Figure 3 Temperature changes after the increase of casting speed from 2.31 to $2.67 \mathrm{~m} \cdot \mathrm{min}^{-1}$

In Table 3 there is a percentage change of temperatures after the increase in casting speed from 2.31 to $2.67 \mathrm{~m} \cdot \mathrm{min}^{-1}$. The highest percentage increases were found at lower parts of the mould. However the increase in the LS at $850 \mathrm{~mm}$ was even negative whereas the RS exhibited the highest increase at all measuring 
locations. A similar situation appears in the IR. As a result of the increase in the casting speed an increase in uniformity of the temperature field in the mould can be observed.

Table 3 Percentage change of the temperature with the increase in the casting speed

\begin{tabular}{|c|c|c|c|c|c|}
\hline \multirow{2}{*}{ Mould wall } & \multicolumn{5}{|c|}{ Distance from mould top } \\
\cline { 2 - 6 } & $\mathbf{2 5 0} \mathbf{~ m m}$ & $\mathbf{4 0 0} \mathbf{~} m$ & $\mathbf{5 5 0} \mathbf{~ m m}$ & $\mathbf{7 0 0} \mathbf{~ m m}$ & $\mathbf{8 5 0} \mathbf{~ m m}$ \\
\hline LS & $1.5 \%$ & $-0.1 \%$ & $0.8 \%$ & $1.4 \%$ & $-0.2 \%$ \\
\hline RS & $5.4 \%$ & $7.7 \%$ & $11.3 \%$ & $13.5 \%$ & $14.6 \%$ \\
\hline OR & $2.2 \%$ & $3.3 \%$ & $4.2 \%$ & $5.4 \%$ & $6.8 \%$ \\
\hline IR & $3.4 \%$ & $4.1 \%$ & $6.8 \%$ & $9.7 \%$ & $14.2 \%$ \\
\hline Average & $3.1 \%$ & $3.7 \%$ & $5.8 \%$ & $7.5 \%$ & $8.9 \%$ \\
\hline
\end{tabular}

The average percentage increase for all walls shows almost linear dependency on the distance from the top of the mould as can be seen in Figure 4.

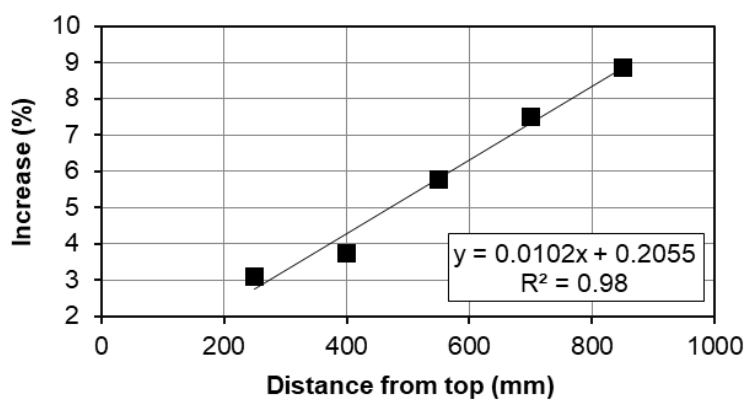

Figure 4 Values of average percentage increases of temperatures after the casting speed increase

The increase in casting speed can also impact a temperature gradient in the mould wall in the longitudinal direction

$\operatorname{grad} \tau=\frac{\left(\tau_{i+1}-\tau_{i}\right)}{\Delta h}$

where:

$\tau_{i}$ - temperature in the $i^{\text {th }}$ distance from the top of the mould $\left({ }^{\circ} \mathrm{C}\right)$

$\Delta h$ - longitudinal distance of neighbouring thermocouples $(\mathrm{m})$.

Obtained gradients are presented in Table 4.

Table 4 Longitudinal temperature gradients in the mould walls

\begin{tabular}{|c|c|c|c|c|c|}
\hline \multirow{3}{*}{$\begin{array}{l}\text { Mould } \\
\text { wall }\end{array}$} & \multicolumn{4}{|c|}{ Distance from mould top ( $\mathrm{mm}$ ) } & \multirow{2}{*}{$\begin{array}{c}\text { Casting speed } \\
\left(\mathbf{m} \cdot \mathbf{m i n}^{-1}\right)\end{array}$} \\
\hline & $250-400$ & $400-550$ & $550-700$ & $700-850$ & \\
\hline & \multicolumn{4}{|c|}{ Gradients $\left(\mathrm{K} \cdot \mathrm{m}^{-1}\right)$} & \\
\hline \multirow{2}{*}{ LS } & -107 & -109 & -84 & 1 & 2.31 \\
\hline & -123 & -102 & -80 & -11 & 2.67 \\
\hline \multirow{2}{*}{ RS } & -353 & -100 & -42 & 23 & 2.31 \\
\hline & -355 & -85 & -34 & 33 & 2.67 \\
\hline \multirow{2}{*}{ OR } & -193 & -58 & -49 & -6 & 2.31 \\
\hline & -189 & -53 & -42 & 4 & 2.67 \\
\hline \multirow{2}{*}{ IR } & -193 & -61 & -107 & -33 & 2.31 \\
\hline & -194 & -43 & -95 & -9 & 2.67 \\
\hline
\end{tabular}


Most gradients decreased after increasing the casting speed. After increasing the casting speed, the average gradient calculated from all measured temperatures decreased by about $6 \%$. Therefore it can be concluded that longitudinal temperature gradients tend to decrease at a higher casting speed. As temperature gradients directly affect thermal stresses and strains in the mould insert their minimization has a favourable effect on the life of the mould insert and the quality of billets.

Differences between mean temperatures measured on the opposite sides of the mould, i.e. differences between the LS-RS and OR-IR, were evaluated in each longitudinal position of installed thermocouples. For this purpose, statistical significances of differences between the arithmetic mean values were checked. Paired sample t-test was used. The series of measured temperatures are almost independent of each other as $\mathrm{R}^{2}$ values for all individual pairs of data sets are less than 0.025 . Temperatures are approximately normally distributed and variables do not contain any outliers. The critical value of a t-distribution for degrees of freedom of $(n-1)=511$ and for a statistical significance 0.05 is 1.965 . The formula of t-test statistic for a paired sample t-test was used

$t=|\bar{X}| \cdot \sigma^{-1} \cdot n^{0,5}$

where:

$$
\begin{aligned}
& \bar{X} \text { - mean value of temperature differences }\left({ }^{\circ} \mathrm{C}\right) \\
& \sigma-\text { standard deviation of temperature differences }\left({ }^{\circ} \mathrm{C}\right) \\
& n-\text { number of values }(-) .
\end{aligned}
$$

As t-test statistic ranging from 3.5 to 99.2 for all pairs of observations are higher than the critical value, it can be stated that the differences between the average temperatures were significant. The same t-test was used to verify the statistical significance between mean values of LS-RS and OR-IR temperature differences for lower and higher casting speeds. All changes of the temperature differences after speed increase were also significant except for one difference between OR-IR at the position $400 \mathrm{~mm}$ bellow the mould top which t-test statistic was 1.7 .

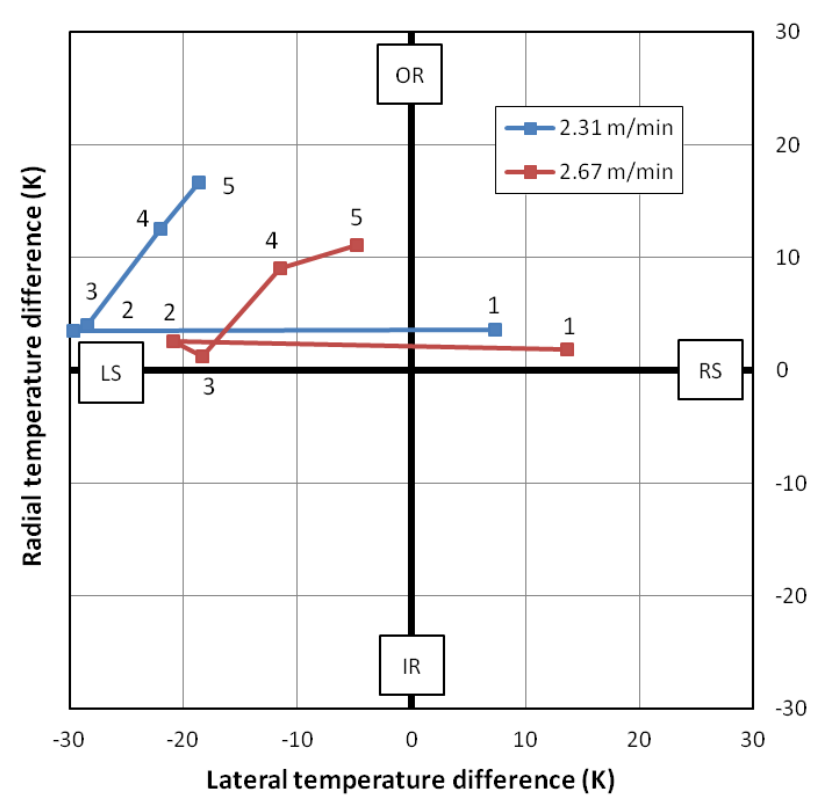

Figure 5 Temperature differences at casting speed $2.31 \mathrm{~m} \cdot \mathrm{min}^{-1}$ and $2.67 \mathrm{~m} \cdot \mathrm{min}^{-1}$

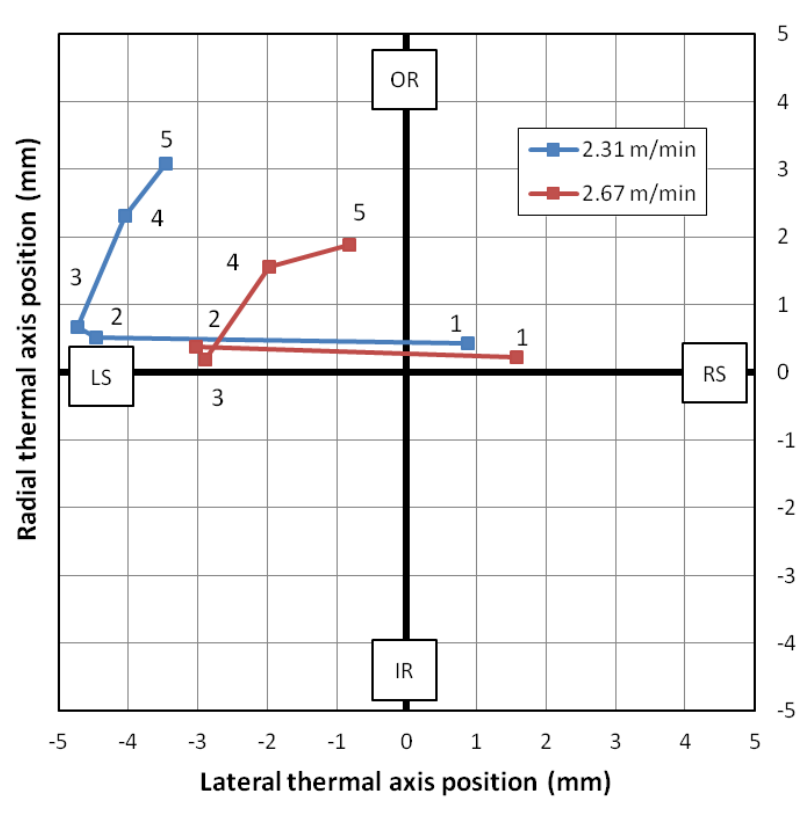

Figure 6 Thermal axis positions at casting speed $2.31 \mathrm{~m} \cdot \mathrm{min}^{-1}$ and $2.67 \mathrm{~m} \cdot \mathrm{min}^{-1}$ 
Temperature differences between the opposite sides can be seen in Figure 5. Data points are marked No. 1 to No. 5 according to the sensor longitudinal position, see Table 2. Each point is determined by a LS-RS and OR-IR difference of mean temperatures. The deviation of each data point from the origin of coordinates characterises unevenness of the thermal field in the transversal section of the mould.

As can be seen from Figure 5, after speed increase the deviations of data points decreased. The largest change appeared at distances of $850 \mathrm{~mm}$ and $700 \mathrm{~mm}$ below the mould top, as the difference between LS-RS and IR-OR temperatures decreased. At closer distances from mould top, smaller changes can be observed because the soft solid shell is pressed against the mould by ferrostatic pressure.

The uniformity of the heat removal in the mould can also be characterized by the so-called thermal axis, see Figure 6 . The position of the thermal axis was calculated analogously to the calculation of the position of the resultant force of parallel forces in mechanics, where the forces here represent temperatures. Deviation of the thermal axis in a certain direction means a higher wall temperature and a higher heat flux. The position of the thermal axis can also be expressed in polar coordinates according to the radius and the polar angle. After increasing the casting speed, the average radius for all measured longitudinal positions decreased from 3.9 $\mathrm{mm}$ to $2.4 \mathrm{~mm}$.

These findings confirm that the so-called thermal axis depends not only on the adjustment of the geometry of the casting machine but it dynamically changes according to casting and cooling parameters. The thermal axis is also affected by a position of the submerged entry nozzle, the uniformity of the distribution of the casting powder, chemical composition of steel and the wear of the mould. The position of the thermal axis affects the uniformity of the solid shell thickness. It is important for a given caster and conditions to keep the thermal axis as close to the mould centreline as possible to ensure symmetry of the mould temperature field. Since the position of the thermal axis changes in time, it is advisable to implement an intelligent mould with on-line temperature monitoring system which helps to keep the casting parameters within optimal limits, as well as to replace the worn mould insert in time. It is important to fine-tune the caster geometry and casting parameters for a given steel grade and keep them constant for most of the casting time.

\section{CONCLUSION}

From evaluation of the obtained data following conclusion can be made. Increase in casting speed increases temperature of the mould walls. The percentage increase of temperatures that was observed, exhibited close to linear dependency on the distance from the mould top. As the casting speed increased, the temperature gradient tended to decrease predominantly. Therefore increase in casting speed led to more uniform temperature field in the mould. Increase in the casting speed had a positive effect on minimizing temperature differences at all distances from mould top as longitudinal temperature gradients decreased. Differences in mould temperatures in transversal direction also decreased when casting speed increased. From the above, it can be concluded that increasing the casting speed improved the uniformity of the mould temperature field, and therefore caused more uniform heat removal from the solidifying steel.

\section{ACKNOWLEDGEMENTS}
This paper originated with the support of grants of the Faculty of Materials Science and Technology, VŠB - TU Ostrava SP2020/34 "Low energy systems and materials in industrial technologies" and SP2020/39 "Specific research in the metallurgical, materials and process engineering".

\section{REFERENCES}

[1] ŠTĚTINA, J., KAVIČKA, F., KATOLICKÝ, J., MAUDER, T., KLIMEŠ, L. Importance of the experimental investigation of a concasting technology. In The Application of Experimental and Numerical Methods in Fluid Mechanics and Energy 2018. Žilina: MATEC Web of Conferences, 2018, pp. 1-6. 
[2] PŘíHODA, M., MOLÍNEK, J., PYSZKO, R., VELIČKA, M., VACULÍK, M. BURDA, J. Heat transfer during cooling of hot surfaces by water nozzles. Metalurgija. 2009, vol. 48, no. 4, pp. 235-238.

[3] KIL PARK, J., SAMARASEKERA, I. V., THOMAS, B.G., YOON, U.S. Analysis of thermal and mechanical behavior of copper mould during thin slab casting. Iron and Steel Society. 2000, vol. 83, pp. 9-21.

[4] ZHANG, X. Investigation of thermal performance of mold copper plate in slab continuous casting. The Open Mechanical Engineering Journal. 2011, vol. 5, pp. 39-42.

[5] JEONG, H., HWANG, J.Y., CHO, J.W. In-depth study of mold heat transfer for the high speed continuous casting process. Metals and Materials. 2016, vol. 22, no. 2, pp. 295-304. 